\title{
Sitting position does not alter minimum alveolar concentration for desflurane
}

\author{
[La position assise ne modifie pas la concentration alvéolaire minimale du \\ desflurane]
}

Chun-Ming Lin MD, ${ }^{*}$ Chieh-Tsai Wu MD, $†$ Shih-Tseng Lee MD, $†$ Tai-Ngar Lui MD, $†$ Chia-Chun Huang MD, ${ }^{*}$ Allen Hon-Lun Li MD PhD, ${ }^{*}$ Anthony G. Doufas MD PhD

Purpose: Hypotension is a common complication of the sitting position during anesthesia, and is often counteracted by decreasing anesthetic depth, thereby exposing patients to the risk of being inadequately anesthetized. Baroreceptor unloading and the consequent sympathoexcitation, as during head up tilt, decreases pain threshold and arouses the central nervous system (CNS), whereas hypotension exerts a direct CNS depressant effect. We estimated the minimal alveolar concentration (MAC) of desflurane for immobility in patients undergoing surgery in the sitting position, in comparison to MAC desflurane for patients having a similar type of surgery in the supine position.

Methods: The Dixon up-and-down method was used to evaluate the MAC for desflurane in patients undergoing cervical spine laminoplasty $(n=24)$ or discectomy $(n=24)$ in the sitting and supine positions, respectively. Logistic regression with co-variate adjustment was employed to examine if the two positions (sitting and supine) have different or share the same concentration vs response relationship for immobility. Monte Carlo simulation was used to calculate $95 \%$ confidence intervals $(\mathrm{Cl})$ for the MAC in each position, and to estimate the difference in MAC (delta MAC) between the sitting and supine positions.

Results: Modeling both sitting [6.54\% (6.50-6.66, 95\% Cl)] and supine $[6.70(6.55-6.8 \mathrm{I})]$ patients as having different MAC concentrations did not significantly improve our simplified model, which treats the two patient groups as one [6.6I (6.52-6.70), delta -2 log likelihood $=2.735, P=0.098]$. Mean delta MAC $(95 \% \mathrm{Cl})$ was $-0.14(-0.30,0.03)$.

Conclusion: The sitting position does not change desflurane anesthetic requirements for immobility.

CAN J ANESTH $2007 / 54: 7 /$ pp 523-530
Objectif: L'hypotension est une complication fréquente de l'anesthésie prodiguée en position assise, et elle est souvent traitée en diminuant la profondeur de l'anesthésie, exposant ainsi les patients au risque d'une anesthésie inadéquate. Le déchargement des barorécepteurs et l'excitation sympathique qui s'ensuit, comme par exemple lors de l'élévation de la tête, diminuent le seuil de douleur et stimulent le système nerveux central (CNS), alors que l'hypotension exerce un effet dépresseur direct sur le CNS. Nous avons évalué la concentration alvéolaire minimale (MAC) du desflurane permettant d'atteindre l'immobilité des patients subissant une chirurgie en position assise, par rapport à la MAC du desflurane pour les patients subissant une chirurgie similaire en décubitus dorsal.

Méthode : La méthode de l'escalier de Dixon a été utilisée pour évaluer la MAC du desflurane chez des patients subissant une laminoplastie de la colonne cervicale $(n=24)$ ou une discectomie $(n=24)$, en position assise et en décubitus dorsal, respectivement. Un modèle de régression logistique avec ajustement des covariables $a$ été employé afin de déterminer si les deux positions (assise et en décubitus dorsal) nécessitent différentes concentrations ou au contraire la même concentration pour l'immobilité. La méthode de Monte-Carlo a été utilisée pour calculer des intervalles de confiance (IC) de $95 \%$ pour la MAC dans chaque position, et pour évaluer la différence de MAC (delta MAC) entre les positions assise et décubitus dorsal.

Résultats: L'hypothèse de base, soit que les patients assis $[6,54 \%(6,50-6,66,95 \%$ IC) $]$ et ceux en décubitus dorsal $[6,70$ (6,55-6,8I)] présentent des concentrations MAC différentes, n'a pas amélioré de façon significative notre modèle simplifié, lequel considère les deux groupes de patients en tant qu'un seul groupe [6,61 (6,52-6,70), delta -2 logarithme du rapport de vraisemblance $=2,735, P=0,098]$. La delta MAC moyenne (95\% IC) a été $-0,14(-0,30,0,03)$.

From the Departments of Anesthesiology* and Neurosurgery, $†$ Chang Gung Memorial Hospital, Chang Gung University College of Medicine, Tao Yuan, Taiwan; and the Department of Anesthesia, $\ddagger$ Stanford University School of Medicine, Stanford, California, USA; and the Outcomes Research Group.

Address correspondence to: Dr. Chun-Ming Lin, Department of Anesthesiology, Chang Gung Memorial Hospital, 5, Fu-Hsing St., Tao

Yuan, Taiwan. E-mail: sam2498@adm.cgmh.org.tw

Accepted for publication March 5, 2007.

Revision accepted April 5, 2007.

This manuscript is accompanied by an editorial. Please see Can J Anesth 2007; 54: 497-500. 
Conclusion : La position assise ne modifie pas les besoins anesthésiques en desflurane pour l'immobilité.

$\mathrm{H}$ YPOTENSION and hemodynamic instability are commonly associated with the sitting position during anesthesia, resulting primarily from a sudden decrease in intrathoracic blood volume. ${ }^{1}$ In order to counteract this physiologic response, anesthesiologists frequently reduce the concentration of inhaled anesthetic, exposing patients to the potential risk of being inadequately anesthetized. It is thus important to investigate the effect of assuming the sitting position on anesthetic requirements.

In awake humans, barostimulation has been shown to decrease pain perception and attenuate skeletal muscle reflexes. ${ }^{2,3}$ Conversely, the sitting position and head-up tilt, which result in baroreceptor unloading, produce an electroencephalogram-determined arousal ${ }^{4,5}$ and decrease current perception threshold. ${ }^{6}$ In animals, the use of vasopressors did not affect minimum alveolar concentration (MAC) of halothane for immobility, ${ }^{7}$ whereas sympathoexcitation, a physiological consequence of baroreceptor unloading, increased MAC for cyclopropane and halothane. ${ }^{8,9}$ On the other hand, reduction of the mean arterial pressure to 50 $\mathrm{mmHg}$ reduced MAC by approximately $20 \%$, possibly due to decreased cerebral perfusion. ${ }^{10}$

Anesthetics generally suppress baroreceptor function in clinically relevant concentrations. ${ }^{11,12}$ However, desflurane exhibits a unique autonomic physiology, which preserves reflex sympathetic responses to acute hypotension in anesthetized humans. ${ }^{13}$ It is thus possible that challenging the baroreceptor reflex via altering body position during desflurane anesthesia mediates a central effect on the anesthetic response, (i.e., increasing anesthetic demand). Nonetheless, sitting position-induced hypotension, ${ }^{14}$ through a decrease in cerebral perfusion, ${ }^{15}$ might exert an opposite effect on anesthetic requirements for immobility.

Thus, we undertook a randomized controlled trial to determine the MAC for desflurane in patients undergoing neck surgery in the sitting position, in comparison with MAC desflurane for patients undergoing similar surgery while supine.

\section{Methods}

Previous simulation studies, using mixed-effects modeling, have shown that the bias in $\mathrm{C}_{50}$ (MAC) estimation is decreased (estimates within $5 \%$ of the true value), even for sparse data (one data point per patient), as long as the total number of patients is 20 or more. ${ }^{16}$ Also, in another simulated MAC experiment, using the Dixon up-and-down method, Paul et al. ${ }^{17}$ found that the bias in the estimation of population MAC does not decrease considerably after obtaining six to ten concentration crossovers.

Thus, after obtaining approval from the Institutional Review Board of Chang Gung Memorial Hospital and written informed consent, we enrolled 50 ASA physical status I and II patients aged between 40 and $60 \mathrm{yr}$, undergoing general anesthesia for elective cervical spine surgery. These patients were scheduled to receive cervical spine laminoplasty in the sitting position $(n=25)$ or cervical spine discectomy in the supine position $(n=25)$, with a skin incision greater than $3 \mathrm{~cm}$ in length.

All enrolled patients had a history of chronic pain due to cervical spine disease and were receiving nonsteroidal anti-inflammatory drugs (NSAIDs). Patients who had taken any NSAIDs up to $12 \mathrm{hr}$ before the time of surgery were excluded from the study. Patients were also excluded if they were receiving opioids, suffering from diabetes, were obese (body mass index $>29 \mathrm{~kg} \cdot \mathrm{m}^{2}$ ), or if there was any contraindication to inhalational anesthetic induction. We restricted enrolment to surgeries scheduled between $8 \mathrm{AM}$ and noon to minimize the circadian influence on anesthetic requirement. ${ }^{18}$

\section{Protocol}

Patients were not given any premedication. Standard monitoring was applied and anesthesia was induced by inhalation of 6-8\% sevoflurane in oxygen. The endtidal concentration of the anesthetic agent was measured with a Datex-AS-5 monitor (Datex-Engstrom, Ohmeda, Helsinki, Finland), which was calibrated at the beginning of each trial. A neuromuscular monitor was attached at the wrist to monitor "train-of-four" response over the distribution of the ulnar nerve. After loss of eyelash reflex, succinylcholine was administered and the trachea was intubated. The anesthetic was then switched to desflurane, and maintained at the selected end-tidal concentration (see below) for at least $45 \mathrm{~min}$ after assuming the designated position for surgery. Patients were mechanically ventilated with $80 \%$ oxygen in nitrogen, to maintain an endtidal $\mathrm{PCO}_{2}$ of $30-35 \mathrm{mmHg}$. A radial artery catheter was placed with the pressure transducer zeroed at the level of patient's ear, while a 200 -mL fluid challenge was administered if systolic blood pressure decreased below $<90 \mathrm{mmHg}$. Core temperature was recorded through a thermocouple inserted into the nasopharynx, while resistive heating was used to maintain 
normothermia. The head of the patients in the sitting position was supported in steel pins applied soon after endotracheal intubation.

Before skin incision, we confirmed that patients had recovered four full twitches in response to supra-maximal stimulation of the ulnar nerve. The first patient in each group was assigned to an end-tidal desflurane concentration (EtDes) of $6 \%$. If this patient moved in response to surgical skin incision, the concentration was increased by $0.5 \%$ desflurane in the subsequent patient of that position group. In contrast, the desflurane concentration for the subsequent patient in that group was decreased by $0.5 \%$ if skin incision did not provoke movement according to the "Dixon up-anddown" method. ${ }^{19}$

\section{Measurements}

An independent investigator blinded to the Et-Des, determined the patient's response to skin incision. A positive response to skin incision was defined by a purposeful movement of one or more extremities. Grimacing or coughing was not considered a purposeful response. Patients were observed for movement for one minute following skin incision. Thereafter, data collection for the study was complete, and the conduct of anesthesia was then left to the discretion of the attending anesthesiologist.

All demographic and morphometric characteristics were recorded. Respiratory and hemodynamic parameters, as well as core temperature, were measured continuously and recorded every five minutes. The time interval, as well as the amount of fluids administered to the patients, from anesthetic induction until skin incision were also recorded.

\section{Data analysis}

Logistic regression was performed with nonlinear mixed effects modeling (NONMEM V, CloboMax LLC, Hanover, MD, USA) to estimate the probability of patient movement in response to skin incision as a function of EtDes. Each movement response to surgical incision was given a score of 0 , and each non-movement response was given a score of 1 . The probability of non-movement response was then calculated as:

$$
P_{i}=\frac{E t D e s_{i}^{\gamma}}{E t D e s_{50 i}{ }^{\gamma}+E t D e s_{i}^{\gamma}}
$$

where $P_{i}$ is the probability of non-movement in the $i$ th individual, EtDes is $_{\mathrm{i}}$ the EtDes in the $i$ th individual and EtDes $_{50 \mathrm{i}}$ is the desflurane concentration in the $i$ th individual associated with $50 \%$ probability of nomovement (MAC). Gamma $(\gamma)$ is the steepness of the concentration $v s$ response relationship, also termed the "Hill coefficient." Inter-individual variability was permitted on EtDes ${ }_{50}$, and was assumed to be lognormally distributed:

$$
E t D e s_{50 i}=E t D e s_{50 p o p} \times e^{\eta E t D e s_{50}}
$$

where $\eta_{\mathrm{EtDes} 50 \mathrm{i}}$ represents the difference between the typical (mean) population value of $\operatorname{EtDes}_{50}\left(\right.$ EtDes $_{50}$ pop $)$ and the individual specific EtDes ${ }_{50}\left(\right.$ EtDes $\left._{50 \mathrm{i}}\right)$. It was assumed that $\eta_{\text {EtDes50i }}$ is a random variable symmetrically distributed around 0 with variance $\omega^{2}$.

If, as defined above, $\mathrm{R}$ is the observed response to surgical incision and $\mathrm{P}$ is the probability of non-movement response, then the probability of each observation was defined as:

Probability of observation $=\mathrm{R} \times \mathrm{P}+(\mathrm{l}-\mathrm{R}) \times(\mathrm{l}-\mathrm{P})$

The probability of non-movement is the probability that the patient will not respond to the stimulus, ranging from 0 when no drug is present to $l$ as the desflurane concentration approaches infinity. The probability of an observation refers to an individual observation during the study. Since P in the model is the probability of non-movement response, then if the patient did not respond, the probability of that observation is P. However, if the patient responded, then the probability of that in the model is 1-P. For example, if no drug is present, then the probability of non-movement is 0 , and the probability of movement is 1 . The probability of the observation depends on what the observation was. NONMEM estimated the model parameters to identify the parameter values that maximized the probability of all of the observations.

The effect of patient position was assessed using the nested model approach. The difference in the 2 log likelihood (-2LL) between two nested models is approximately Chi-square distributed and can be used for significance tests. Each added parameter was considered significant $(P<0.05$, with one degree of freedom) if it produced a reduction of 3.84 points in the -2LL of the simplified model.

\section{Monte Carlos simulation}

Monte Carlo simulation was used to determine the confidence intervals (CI) for the MAC values in the sitting and supine positions, as well as for the difference between the two (delta MAC), according to the following steps (Prism 4.0c, GraphPad Software, Inc., San Diego, CA, USA): ${ }^{20}$

1) We generated an ideal data set. We used the same desflurane concentrations ( $\mathrm{X}$ values) with the actual data. We generated movement responses ( $\mathrm{Y}$ 

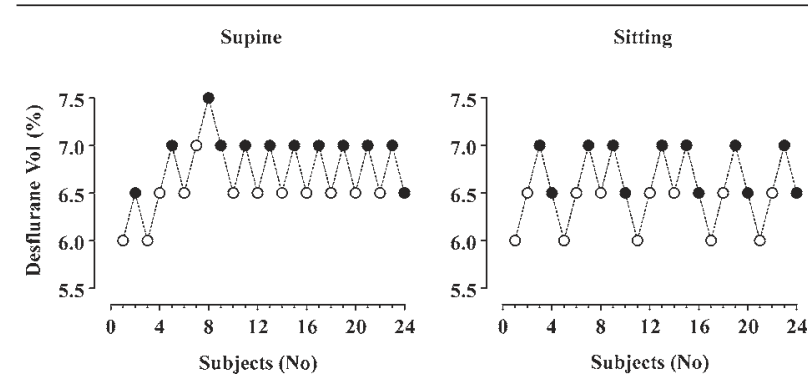

FIGURE 1 End-tidal desflurane concentrations that were tested in the sitting and supine positions. Each patient was evaluated only once at a predetermined desflurane concentration, according to the Dixon paradigm. Open circles indicate patients who moved in response to surgical incision, whereas closed circles indicate patients who did not move. Horizontal dotted lines represent the respective MAC values for each patient population. $\mathrm{MAC}=$ minimal alveolar concentration; No $=$ patient sequence number.

values) using the same model we used to fit the experimental data. We used the best-fit values of MAC from non-linear regression of the experimental data, as the ideal parameters to generate the ideal data.

2) We added random scatter. To each ideal point, we added random scatter drawn from a Gaussian distribution with a mean of 0 and SD of $35 \%$, which equals the best-fit estimate of the SD of the residuals reported by the non-linear regression of our experimental data.

3) We fit the simulated data with non-linear regression, and recorded the best-fit value for desflurane MAC.

4) We repeated steps 2 and 3 1,000 times. Each time, we computed new random numbers so that each of the simulated experiments had different data. These simulated data sets are similar to what we would have observed, if we had repeated the experiment 1,000 times.

5) We found the $2.5^{\text {th }}$ and $97.5^{\text {th }}$ percentile values from the distributions (1,000 values) of desflurane MAC for each patient position. The range between these values is the $95 \%$ CI. The difference between the MAC in the sitting and supine positions (delta MAC) was presented as the mean of the differences between the 1,000 randomly ordered individual MAC values, while the $95 \%$ CI for delta MAC was calculated as described above.

All the measured parameters were compared between the two position groups using unpaired Student's $t$ and Mann Whitney (time from induction to incision) tests. Gender was compared using
TABLE I Demographics, morphometrics and potential confounding factors

\begin{tabular}{|c|c|c|c|}
\hline Patient position & $\begin{array}{l}\text { Sitting } \\
(n=24)\end{array}$ & $\begin{array}{l}\text { Supine } \\
(n=24)\end{array}$ & P value \\
\hline Age $(\mathrm{yr})$ & $52 \pm 6$ & $52 \pm 4$ & 0.45 \\
\hline Gender (male/female) & $12 / 12$ & $11 / 13$ & 1.00 \\
\hline Body mass index $\left(\mathrm{kg} \cdot \mathrm{m}^{-2}\right)$ & $23.2 \pm 2.1$ & $23.2 \pm 2.4$ & 0.47 \\
\hline $\begin{array}{l}\text { Time from induction to } \\
\text { incision }(\mathrm{min})\end{array}$ & $55(50-65)$ & $55(50-60)$ & 0.059 \\
\hline Core temperature $\left({ }^{\circ} \mathrm{C}\right)$ & $35.9 \pm 0.1$ & $35.9 \pm 0.1$ & 0.31 \\
\hline End-tidal $\mathrm{CO}_{2}(\mathrm{mmHg})$ & $36 \pm 3$ & $36 \pm 3$ & 0.42 \\
\hline Heart rate (beats. $\mathrm{min}^{-1}$ ) & $57 \pm 4$ & $69 \pm 2$ & 0.008 \\
\hline $\begin{array}{l}\text { Systolic arterial pressure } \\
(\mathrm{mmHg})\end{array}$ & $88 \pm 5$ & $99 \pm 7$ & 0.006 \\
\hline $\begin{array}{l}\text { Diastolic arterial pressure } \\
(\mathrm{mmHg})\end{array}$ & $48 \pm 7$ & $59 \pm 8$ & 0.002 \\
\hline $\begin{array}{l}\text { Mean arterial pressure } \\
(\mathrm{mmHg})\end{array}$ & $61 \pm 6$ & $73 \pm 7$ & 0.003 \\
\hline $\begin{array}{l}\text { Fluids administered until } \\
\text { incision }(\mathrm{mL})\end{array}$ & $769 \pm 26$ & $671 \pm 23$ & 0.01 \\
\hline
\end{tabular}

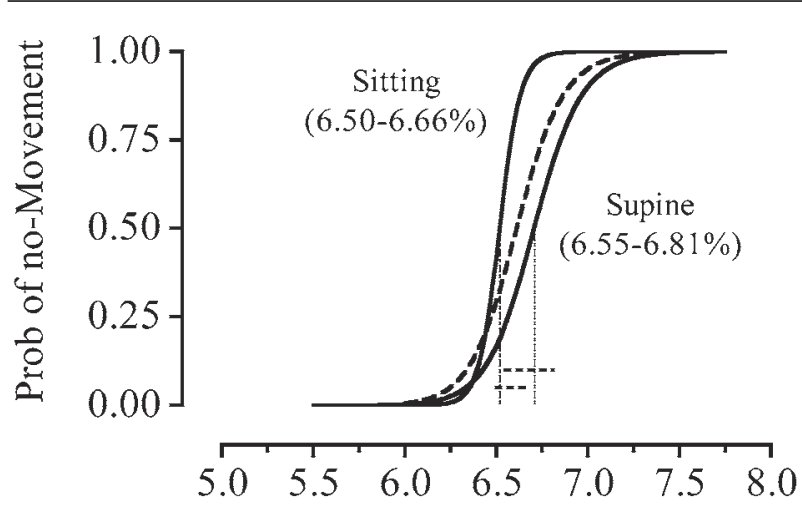

End-Tidal Desflurane Vol (\%)

FIGURE 2 Logistic regression curves fitting the probability of non-movement as a function of desflurane concentration in the sitting and supine positions. Vertical dashed lines indicate MAC values, while horizontal lines indicate the $95 \%$ confidence intervals for those estimates (also reported in parentheses). The desflurane concentration $v s$ response relationship for immobility is essentially the same in the sitting and supine positions and not different from that which characterizes the patient population as a whole ( sitting plus supine, dashed-line curve in the middle). MAC = minimal alveolar concentration; Prob = probability.

Fisher's exact test. Data are presented as means \pm SDs or medians (range); $P<0.05$ was considered statistically significant. 
TABLE II Best-fit values for the desflurane MAC $\left(\right.$ EtDes $\left._{50}\right)$ and steepness $(\gamma)$ of the concentration vs response relationship for the supine and sitting position

\begin{tabular}{|c|c|c|c|c|c|c|c|}
\hline \multicolumn{2}{|c|}{$\begin{array}{l}\text { Model } \\
\text { parameters }(N)\end{array}$} & \multirow[t]{2}{*}{$\begin{array}{l}\text { EtDes }_{50} \\
(95 \% \mathrm{CI})\end{array}$} & & \multicolumn{2}{|c|}{$\operatorname{Gamma}(\gamma)$} & \multirow[t]{2}{*}{$\begin{array}{l}\text { Minimum } \\
\text { objective } \\
\text { value }\end{array}$} & \multirow{2}{*}{$\Delta-2 L L$} \\
\hline $\mathrm{EtDes}_{50}$ & $\gamma$ & & & & & & \\
\hline \multirow[t]{2}{*}{1} & 1 & & $6.61(6.52-6.70)$ & \multirow{5}{*}{$\begin{array}{l}\text { Supine } \\
\text { Sitting }\end{array}$} & 51 & 35.991 & \\
\hline & & & & & 50 & & \\
\hline \multirow[t]{3}{*}{1} & 2 & & $6.61(6.52-6.71)$ & & & 35.983 & -0.008 \\
\hline & & & & & 54 & & \\
\hline & & Supine & $6.70(6.55-6.82)$ & & & & \\
\hline \multirow[t]{3}{*}{2} & 1 & & & & 63 & 33.708 & -2.283 \\
\hline & & Sitting & $6.54(6.50-6.66)$ & & & & \\
\hline & & Supine & $6.70(6.55-6.81)$ & & 50 & & \\
\hline \multirow[t]{2}{*}{2} & 2 & & & & & 33.256 & -2.735 \\
\hline & & Sitting & $6.54(6.50-6.66)$ & & 245 & & \\
\hline
\end{tabular}

\section{Results}

A total of 52 patients were screened and subsequently enrolled. One seated patient did not complete the study because of hypotension during the equilibrium period, and one patient in the supine group was excluded because of difficulty with tracheal intubation. Two patients (one in each group) received a desflurane concentration different from that which was designated, and were therefore subsequently excluded from the analysis (Figure 1).

Demographic and morphometric characteristics, as well as the time interval from anesthetic induction until surgical incision did not differ between position groups. The three surgeons who were involved in the study were equally distributed between the two patient groups, and had similar operating experience. Also, the surgical incisions in the two groups were of similar type and length.

Heart rate and blood pressure were significantly lower in the sitting compared to supine position (Table I). The MAC for desflurane did not change between the sitting $[6.54 \%(6.50-6.66,95 \% \mathrm{CI})]$ and supine $[6.70(6.55-6.81)]$ position (Figure 2). Modeling the two patient populations as having different concentration $v s$ response relationships did not significantly improve our simplified model, which treats the two patient groups as having the same MAC [6.61 (6.52-6.70), delta $-2 \mathrm{LL}=2.735, P=0.098$, (Table II)].

Figure 3 shows the histograms for the 1,000 Monte Carlo simulations of our observed data using the best-

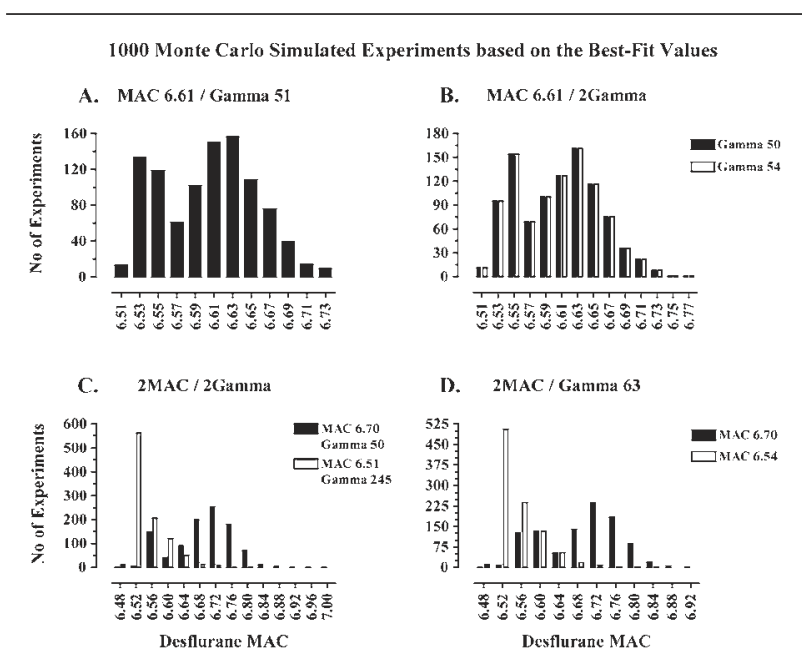

Figure 3 Histograms presenting the MAC values from the Monte Carlo simulated experiments. One thousand simulations were performed for each one of the tested models (see also Table II): 1MAC/1Gamma (A), 1MAC/2Gamma (B), $2 \mathrm{MAC} / 2 \mathrm{Gamma}(\mathrm{C})$, and $2 \mathrm{MAC} / 1 \mathrm{Gamma}(\mathrm{D}) . \mathrm{N}=$ number.

fit values and a random scatter as described above. Delta MAC for the $2 \mathrm{MAC} / 1$ Gamma model was -0.14 $(-0.29,0.04)$, while for the $2 \mathrm{MAC} / 2$ Gamma model delta MAC was $-014(-0.30,0.03)$, (Figure 4$)$. 


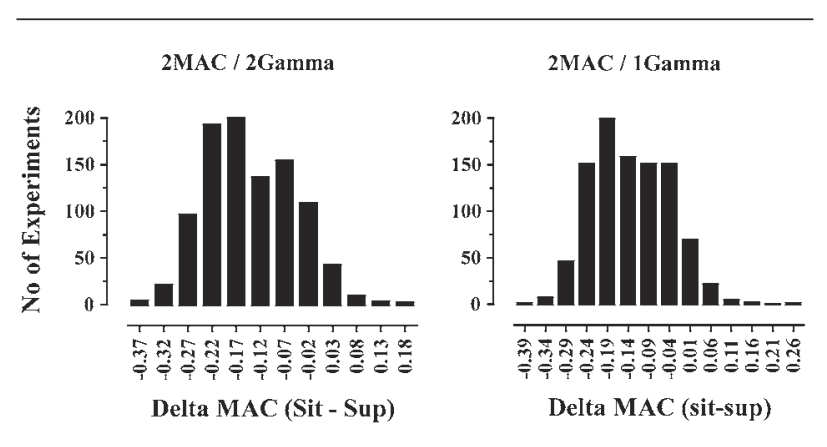

FIGURE 4 Histograms presenting the difference in MAC (delta MAC) between sitting and supine positions, as this has been determined after 1,000 simulated experiments for the $2 \mathrm{MAC} / 2 \mathrm{Gamma}$ and $2 \mathrm{MAC} / 1 \mathrm{Gamma}$ tested models. $\mathrm{MAC}=$ minimal alveolar concentration; $\mathrm{No}=$ patient sequence number; sit $=$ sitting position; $\sup =$ supine position.

\section{Discussion}

Minimum alveolar concentration for desflurane does not differ between the sitting and supine position in patients undergoing cervical spine surgery. Logistic regression analysis with co-variate adjustment showed that these two patient populations share the same desflurane concentration $p s$ response relationship for immobility. One thousand simulated repetitions of the experiment, using the Monte Carlo method, showed that in no case did the difference between MAC values in the sitting and supine positions exceed $0.4 \%$ of desflurane. Thus, our study is appropriately powered to demonstrate the absence of a clinically meaningful difference $(\geq 20 \%$, or about $1.3 \%$ of desflurane) in MAC between the two patient positions. This important finding indirectly emphasizes the potential risk for under-anesthetizing patients when hypotension due to sitting position is counteracted by decreasing the concentration of inhaled anesthetics.

Activation of central baroreceptors in the awake state exerts a general inhibition on the central nervous system, ${ }^{2,3}$ while baroreceptor unloading has the opposite effect. ${ }^{4-6}$ The underlying neural pathway for these effects is not completely understood, but theory holds that supraspinal sites responsible for the integration of autonomic and somatic responses are primarily involved. ${ }^{21,22}$ Although MAC is largely determined by the workings of the spinal cord ${ }^{23}$ recent evidence suggest that supraspinal contribution is also an important modulatory pathway. ${ }^{24,25}$

The extent to which a physiological effector such as hypotension can mediate a central effect via barore- ceptor deactivation depends on the functional integrity of the baroreflex arc itself. General anesthetics reduce baroreceptor sensitivity and inhibit related autonomic physiology in a dose-dependent manner. ${ }^{11,12}$ As a result, vasopressors, which do not cross blood brain barrier, do not affect halothane MAC in animals, ${ }^{7}$ whereas reduction of the mean arterial pressure to 50 $\mathrm{mmHg}$ decreases MAC by approximately $20 \%$, possibly due to decreased cerebral perfusion. ${ }^{10}$

In humans, despite the fact that desflurane inhibits cardiac baroslopes in a concentration-dependent manner, the drug has been shown to preserve reflex increases in sympathetic activation as a response to a hypotensive stimulus. Characteristically, the sympathetic baroslopes at 1.5-MAC desflurane are comparable to those encountered in the awake state. ${ }^{13}$ Although we did not assess sympathetic indices in our patients, hypotension combined with a lower heart rate in the sitting position does not support activation of a sympathetic reflex. In contrast, activation of a cardio-inhibitory reflex, which, by increasing vagal tone, aims to maintain adequate ventricular filling in the face of a sudden decrease in the preload, ${ }^{26,27}$ is a likely explanation. This physiologic response is frequently invoked when sudden redistribution of the central blood volume to the splanchnic circulation and lower extremities considerably decreases cardiac preload, especially in the hypovolemic patient. ${ }^{26}$

In the current investigation, the sitting position decreased heart rate by 12 beats. $\mathrm{min}^{-1}$ and mean arterial pressure by $12 \mathrm{mmHg}$, a level which is considered to be approximately $10 \mathrm{mmHg}$ below the proposed lower limit of cerebral autoregulation. ${ }^{28} \mathrm{~A}$ response of this magnitude is commonly encountered in the sitting popstion $^{14,29}$ and usually results in a small decrease of cerebral perfusion, ${ }^{15,30}$ which, presumably, is not enough to affect volatile anesthetic requirements.

A limitation of our study was that patients were not randomly assigned to the sitting or supine position. Body position during surgery was selected based on the type of the procedure. Nonetheless, a comparison between the two patient groups did not reveal any difference in any of the potential confounding factors, except those directly related to the physiology of altering body position. The overestimation of $\gamma$, as shown in Table II, by mixed-effects modeling (NONMEM) when sparse data are employed, has been described previously. However, as simulation experiments have shown, sparse data did not have the same effect on $\mathrm{C}_{50}$ (MAC) estimates, which remained unbiased. ${ }^{16}$ Therefore, we believe that for the purpose of our study, the more than adequate number of crossovers $^{16,17}$ played a more important role in reducing 
the bias of MAC, than the potentially destabilizing effect of an inflated $\gamma$.

In conclusion, we have demonstrated that for ASA physical status I and II patients between 40-60 yr of age who undergo cervical spine surgery, the sitting position does not alter desflurane anesthetic requirements for immobility.

\section{References}

1 Bubre W, Weyland A, Bubre K, et al. Effects of the sitting position on the distribution of blood volume in patients undergoing neurosurgical procedures. $\mathrm{Br} \mathrm{J}$ Anaesth 2000; 84: 354-7.

2 Rau H, Brody S, Brunia CH, Damen EP, Elbert T. Activation of carotid baroreceptors inhibits spinal reflexes in man. Electroencephalogr Clin Neurophysiol 1993; 89: 328-34.

3 Dworkin BR, Elbert T, Rau H, et al. Central effects of baroreceptor activation in humans: attenuation of skeletal reflexes and pain perception. Proc Natl Acad Sci USA 1994; 91: 6329-33.

4 Caldwell JA, Prazinko B, Caldwell JL. Body posture affects electroencephalographic activity and psychomotor vigilance task performance in sleep-deprived subjects. Clin Neurophysiol 2003; 114: 23-31.

5 Cole RJ. Postural baroreflex stimuli may affect EEG arousal and sleep in humans. J Appl Physiol 1989; 67: 2369-75.

6 Shimoda $O$, Ikuta $\Upsilon$. The current perception thresholds vary between horizontal and 70 degrees tilt-up positions. Anesth Analg 2000; 91: 398-402.

7 Steffey EP, Eger EI. The effect of seven vasopressors of halothane MAC in dogs. Br J Anaesth 1975; 47: 435-8.

8 Johnston RR, White PF, Eger EI 2nd. Comparative effects of dextroamphetamine and reserpine on halothane and cyclopropane anesthetic requirements. Anesth Analg 1975; 54: 655-9.

9 Mueller RA, Smith RD, Spruill WA, Breese GR. Central monaminergic neuronal effects on minimum alveolar concentrations (MAC) of halothane and cyclopropane in rats. Anesthesiology 1975; 42: 143-52.

10 Tanifuji $\Upsilon$, Eger EI 2nd. Effect of arterial hypotension on anaesthetic requirement in dogs. Br J Anaesth 1976; 48: 947-52.

11 Sato $M$, Tanaka M, Umehara S, Nishikawa T. Baroreflex control of heart rate during and after propofol infusion in humans. Br J Anaesth 2005; 94: 577-81.

12 Tanaka $M$, Nishikawa T. The concentration-dependent effects of general anesthesia on spontaneous baroreflex indices and their correlations with pharmacological gains. Anesth Analg 2005; 100: 1325-32.
13 Ebert TJ, Perez F, Uhrich TD, Deshur MA. Desfluranemediated sympathetic activation occurs in humans despite preventing hypotension and baroreceptor unloading. Anesthesiology 1998; 88: 1227-32.

14 Porter JM, Pidgeon C, Cunningham AJ. The sitting position in neurosurgery: a critical appraisal. $\mathrm{Br} \mathrm{J}$ Anaesth 1999; 82: 117-28.

15 Tindall GT, Craddock A, Greenfield JC Jr. Effects of the sitting position on blood flow in the internal carotid artery of man during general anesthesia. J Neurosurg 1967; 26: 383-9.

16 Lu W, Ramsay JG, Bailey JM. Reliability of pharmacodynamic analysis by logistic regression: mixed-effects modeling. Anesthesiology 2003; 99: 1255-62.

17 Paul M, Fisher DM. Are estimates of MAC reliable? Anesthesiology 2001; 95: 1362-70.

18 Munson ES, Martucci RW, Smith RE. Circadian variations in anesthetic requirement and toxicity in rats. Anesthesiology 1970; 32: 507-14.

19 Dixon WJ. Quantal-response variable experimentation: the up-and-down method. In: McArthur JW, Colton T (Eds). Statistics in Endocrinology. MIT Press; 1970: 251-67.

20 Motulsky H, Christopoulos A. Fitting Models to Biological Data Using Linear and Nonlinear Regression. A Practical Guide to Curve Fitting. NY: Oxford University Press; 2004.

21 Rau H, Elbert T. Psychophysiology of arterial baroreceptors and the etiology of hypertension. Biol Psychol 2001; 57: 179-201.

22 Craig $A D$. How do you feel? Interoception: the sense of the physiological condition of the body. Nat Rev Neurosci 2002; 3: 655-66.

23 Antognini JF, Carstens E. In vivo characterization of clinical anaesthesia and its components. $\mathrm{Br} \mathrm{J}$ Anaesth 2002; 89: 156-66.

24 Jinks SL, Dominguez CL, Antognini JF. Drastic decrease in isoflurane minimum alveolar concentration and limb movement forces after thoracic spinal cooling and chronic spinal transection in rats. Anesthesiology 2005; 102: 624-32.

25 Stabernack C, Zhang Y, Sonner JM, Laster M, Eger EI 2 nd. Thiopental produces immobility primarily by supraspinal actions in rats. Anesth Analg 2005; 100 : 128-36.

26 Campagna JA, Carter C. Clinical relevance of the Bezold-Jarisch reflex. Anesthesiology 2003; 98: 125060.

27 Sander-Jensen K, Marving J, Secher NH, et al. Does the decrease in heart rate prevent a detrimental decrease of the end-systolic volume during central hypovolemia in man? Angiology 1990; 41(9 Pt 1): 687-95.

28 Drummond JC. The lower limit of autoregulation: 
time to revise our thinking? Anesthesiology 1997; 86: 1431-3.

29 Marshall WK, Bedford RF, Miller ED. Cardiovascular responses in the seated position--impact of four anesthetic techniques. Anesth Analg 1983; 62: 648-53.

30 Fuchs G, Schwarz G, Kulier A, Litscher G. The influence of positioning on spectroscopic measurements of brain oxygenation. J Neurosurg Anesthesiol 2000; 12: 75-80.

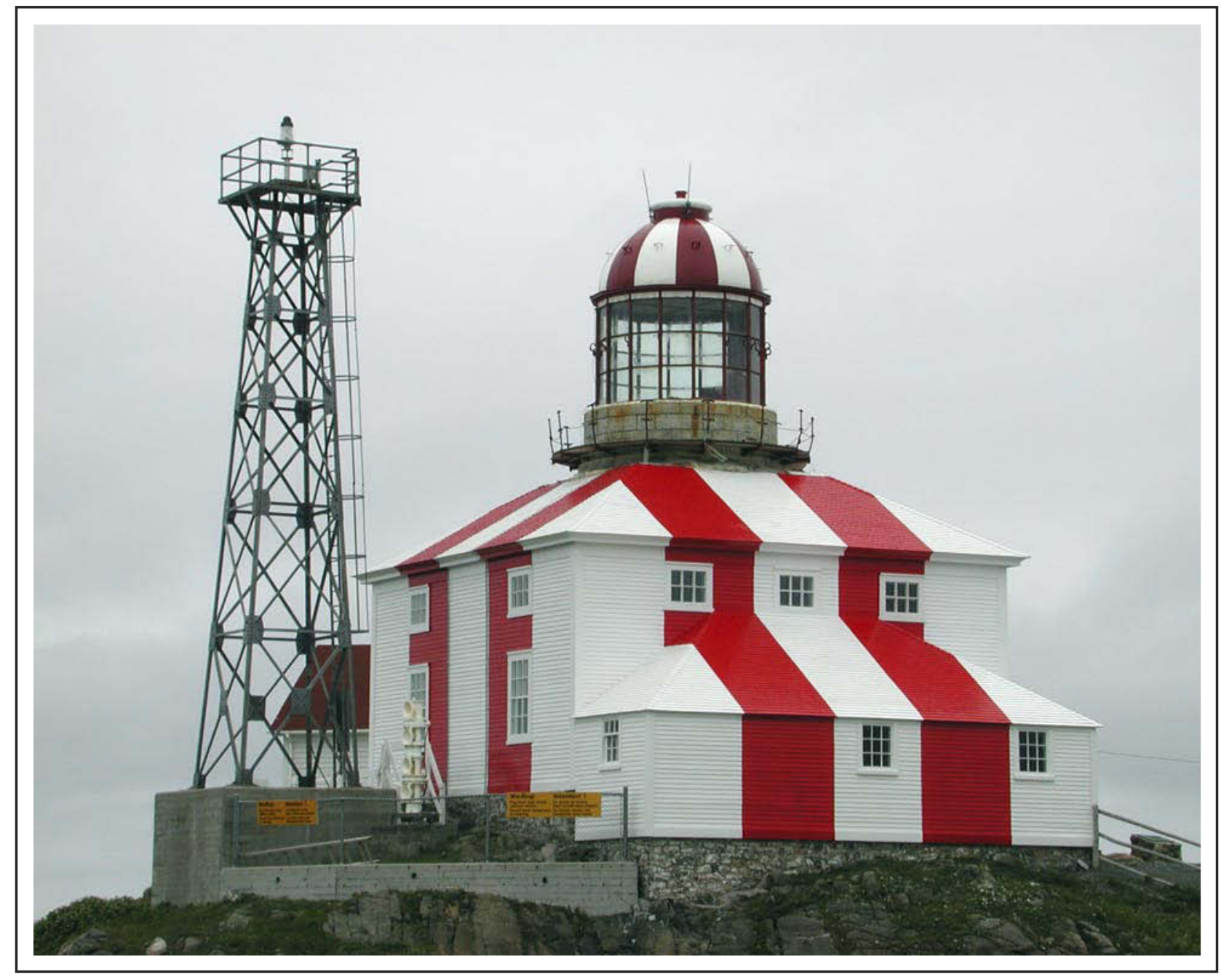

Lighthouse Bonavista - Newfoundland 